\title{
A FORMAÇÃO PROFISSIONAL DAS JUVENTUDES BRASILEIRAS: AVANÇOS E PERSPECTIVAS NAS INTERLOCUÇÕES ENTRE EDUCAÇÃO E TRABALHO
}

\author{
FORMACIÓN PROFESIONAL DE LA JUVENTUD BRASILEÑA: AVANCES Y \\ PERSPECTIVAS EN LAS INTERLOCCIONES ENTRE LA EDUCACIÓN Y EL \\ TRABAJO
}

\section{VOCATIONAL TRAINING OF BRAZILIAN YOUTH: ADVANCES AND PROSPECTS IN THE INTERLOCTIONS BETWEEN EDUCATION AND WORK}

\author{
Lucian da Silva BARROS ${ }^{1}$ \\ Elizabete Cristina COSTA-RENDERS ${ }^{2}$
}

RESUMO: O presente texto tem como objetivo discutir a formação profissional de jovens no Brasil, em especial jovens aprendizes, conforme o preconizado pela lei $n^{\mathbf{o}} 10.097 / 2000$. A metodologia utilizada foi a de revisão bibliográfica e documental, com autores no campo da sociologia, da economia e da educação. Partindo de uma leitura histórica, buscou-se analisar a evolução das políticas de trabalho voltadas a este público e as ações educacionais a elas relacionadas. Este estudo resultou na percepção de que a visão assistencialista vai, ao longo da história, dando espaço a uma noção de proteção integral, com atenção especial dada ao Estatuto da Criança e do Adolescente e mais recentemente ao Estatuto da Juventude. A ação educacional voltada aos jovens tem buscado atualmente o desenvolvimento de competências não somente profissionais, mas também humanas, que compreendem os jovens como cidadãos, pertencentes e atuantes na sociedade.

PALAVRAS-CHAVE: Juventudes. Formação profissional. Trabalho. Educação profissional. Inclusão Social.

RESUMEN: Este texto tiene como objetivo analizar la formación profesional de los jóvenes en Brasil, especialmente los jóvenes aprendices, según lo recomendado por la ley 10.097 / 2000. La metodología utilizada fue la de revisión bibliográfica y documental, con autores en el campo de la sociología, la economía y la educación. A partir de una lectura histórica, buscamos analizar la evolución de las políticas de trabajo dirigidas a este público y las acciones educativas relacionadas con ellas. La visión del bienestar pasa por la historia dando paso a una noción de protección integral, con especial atención al Estatuto del Niño y el Adolescente y más recientemente al Estatuto de la Juventud. La acción educativa dirigida a los jóvenes busca actualmente el desarrollo de habilidades no solo profesionales, sino también humanas, que entiendan a los jóvenes como ciudadanos, pertenecientes y activos en la sociedad.

\footnotetext{
1 Universidade Municipal de São Caetano do Sul (USCS), São Caetano do Sul - SP - Brasil. Psicólogo, Especialista em educação (USP) e Mestre em Educação (PPGE-USCS). ORCID: https://orcid.org/0000-00017592-3473. E-mail: luciasbarros@gmail.com

${ }^{2}$ Universidade Municipal de São Caetano do Sul (USCS), São Caetano do Sul - SP - Brasil. Professora do Programa de Pós-Graduação em Educação (PPGE-USCS), Doutora e Pós-doutora em Educação (UNICAMP). ORCID: https://orcid.org/0000-0002-1219-9382. E-mail: elizabetecostarenders@ gmail.com
} 
PALABRAS CLAVE: Jóvenes. Formación professional. Trabajo. Educación professional. Inclusión social.

ABSTRACT: This text aims to discuss the professional formation of young people in Brazil, especially young apprentices, as recommended by law 10.097/2000. The methodology used was that of bibliographic and documentary revision, with authors in the field of sociology, economics and education. From a historical reading, we sought to analyze the evolution of work policies aimed at this audience and the educational actions related to them. The welfare view goes through history giving way to a notion of integral protection, with special attention given to the Child and Adolescent Statute and more recently to the Youth Statute. The educational action aimed at young people is currently seeking the development of skills not only professional, but also human, which understand young people as citizens, belonging and active in society.

KEYWORDS: Youths. Professional qualification. Work. Professional education. Social inclusion.

\section{Introdução}

A formação para o trabalho é uma pauta constante quando nos referimos à educação de jovens no Brasil. Incluir as juventudes brasileiras no mercado de trabalho formal, em especial, a socialmente vulnerável, parece ser um desafio presente nas agendas de governo nas últimas décadas. Esta inclusão visa reduzir as mazelas das desigualdades sociais existentes em nosso país, possibilitando acesso ao trabalho e à educação para as novas gerações.

O objetivo deste texto é discorrer sobre os aspectos envolvidos na formação profissional dos jovens trabalhadores no Brasil, tendo como pano de fundo as políticas e as ações educacionais para este público ao longo das décadas. A metodologia utilizada foi a revisão bibliográfica, na qual buscou-se compreender, por meio de uma análise histórica das políticas e leis, os avanços encontrados nesta área, que objetivaram, cada vez mais, garantir uma formação profissional integral, que abarcasse as dimensões sociais, econômicas, educacionais e psicológicas da vida dos jovens.

Iniciamos esta discussão apresentando diversas visões sobre o lugar histórico do trabalho dos jovens no Brasil e os movimentos no campo educativo que as acompanharam. Em uma visão assistencialista, o jovem era encarado como um problema social, o qual deveria ser mantido constantemente ocupado, executando nas empresas funções mecânicas e, às vezes, rudimentares. O trabalho seria, para o jovem, a única forma de escapar da criminalidade e de exclusão social. A utilização desta força de trabalho, em muitos momentos foi vista como meio 
de reinserção de jovens desviantes, tidos como delinquentes. Aos jovens pobres que não poderiam estudar, cabia o trabalho. Por vezes, precário e sem direitos.

Tais visões foram acompanhadas por concepções de educação, que consideravam, apenas, o fazer profissional voltado para a práxis, ou seja, a ação concreta, em detrimento da compreensão do papel social da educação na vida dos jovens. Estas concepções imperaram por muito tempo, impulsionando inclusive muitas ações do governo e da sociedade civil. Mas isto foi se modificando, dando espaço para a concepção do jovem trabalhador como um profissional em desenvolvimento, o qual necessita ser protegido de maneira integral, com uma educação voltada a sua formação como cidadão, inserido em uma sociedade que ele é capaz de compreender e transformar.

\section{Revisão das políticas sobre o trabalho do jovem no Brasil}

Segundo Felícia Picanço (2015), a presença da juventude como força de trabalho é marcante na história recente do Brasil. Em sua análise, diferentes papéis relativos à condição de ser jovem foram sendo construídos ao longo das décadas, principalmente, a partir de uma elevada desigualdade socioeconômica, muitas vezes, realimentada pela própria condição de ser um jovem trabalhador. Esta autora chama atenção em sua discussão, para o conceito de Trabalho Decente (TD) e para a precariedade em que os jovens foram sendo inseridos, historicamente, no mundo laboral. Sem haver uma preocupação efetiva como os modos e mecanismos desta inserção, os mais jovens foram sendo levados a situações de trabalho subhumanas, longe do que seria considerado um trabalho decente.

No Brasil, o trabalho das crianças, adolescentes e jovens sempre esteve fortemente presente. Além disso, o padrão de inserção ocupacional dos jovens é marcado pela precariedade. Tal precariedade pode ser entendida de duas formas: trata-se tanto da tendência a estar nas piores ocupações no mercado de trabalho, quanto ter a pior remuneração e relações de trabalho instáveis quando comparados aos adultos em ocupações semelhantes (PICANÇO, 2015, p. 571).

De acordo com Picanço (2015), os jovens que apresentam maior propensão a trabalhar são aqueles pertencentes às famílias mais pobres e, por vezes, menos escolarizados. Mesmo que jovens mais escolarizadas e menos vulneráveis socioeconomicamente também almejem adentrar ao mercado de trabalho, torna-se relevante observar que, para estes, a inserção ocorre geralmente mais tardiamente (por volta dos 20 anos) e com maior poder de escolha quanto ao tipo de trabalho a ser desenvolvido. Os jovens mais pobres ingressam no trabalho mais 
precocemente e em piores condições. Neste sentido, segundo Picanço, "o trabalho entre os jovens figura como um elemento produtor e reprodutor de desigualdades em vários aspectos" (2015, p. 569).

De acordo com Laís Abramo (2013, p.41), a “juventude brasileira é uma juventude trabalhadora”. Apresentando dados da $\mathrm{PNAD} / \mathrm{IBGE}^{3}$ de 2009, ela aponta que mais de 34 milhões de adolescentes ou jovens do país trabalhavam ou mesmo estavam à procura de oportunidades de empregos formais ou informais. Para esta autora, há um esforço crescente por parte dos jovens para combinar trabalho e estudo, sendo que a democratização do acesso à escola e a presença dos jovens no ensino médio, não eliminou as experiências no campo do trabalho.

Os jovens continuam propensos à entrada precoce no trabalho, contudo, aqueles que pertencem a famílias com maiores rendimentos, são, ainda, os que apresentam melhores índices na obtenção de empregos de melhor qualidade. Tal aspecto acaba por fomentar a desigualdade, pois os jovens provenientes de famílias mais empobrecidas ficam com os piores postos de trabalho, que requerem menos qualificação e, por consequência, remuneram menos. Desta forma, a "elevação da escolaridade e a melhoria da sua qualidade é um aspecto central para a construção de uma trajetória de trabalho decente" (ABRAMO, 2013, p. 41) para as juventudes brasileiras.

O trabalho na juventude é, segundo Silvio Bock (2010), destinado aos filhos das classes mais pobres, sem haver no campo das políticas educacionais e de formação de mão de obra no Brasil, espaços de discussões, por exemplo, de temáticas como a escolha profissional. Acrescentemos, ainda, que a preocupação, durante muito tempo, foi oferecer vagas de emprego, sem apontar para outras questões referentes à vida dos jovens trabalhadores. O jovem pobre deve trabalhar, sendo que o trabalho figura como elemento central em suas vidas, enquanto outras questões e temáticas como artes, esporte e lazer, aparecem como periféricos. Portanto, são negligenciados pelas políticas públicas e pelas agendas de governo para as juventudes.

Às pessoas empobrecidas da nação brasileira restava o destino do trabalho precoce, e quando uma qualificação profissional era cogitada, sempre aparecia como alternativa de segunda linha o aprendizado de habilidades para o desempenho de um ofício (BOCK, 2010, p. 19).

É possível observar que as juventudes, pertencentes às classes mais abastadas financeiramente da sociedade brasileira, prolongam sua vida acadêmica e retardam cada vez

\footnotetext{
${ }^{3}$ Pesquisa Nacional por Amostra de Domicílios Contínua/Instituto Brasileira de Estatísticas.
} 
mais sua entrada no mercado formal de trabalho, com vistas a sua melhor qualificação. As juventudes pobres, por sua vez, são quase que obrigadas, precocemente, a procurar empregos, muitas vezes, informais e precários, para assim garantir itens básicos de sua sobrevivência. Para Bock (2010), enquanto os filhos das classes ricas ocuparão futuramente os melhores postos de trabalho, possivelmente mais bem remunerados, restarão, para os jovens mais pobres, os subempregos. Segundo este autor, não temos nos preocupado, enquanto sociedade, com a formação educacional e humana, constituindo propostas reais que levem em conta diferentes contextos de vida das juventudes deste país.

Dayrell (2007) destaca o quanto o mundo do trabalho surge de maneira expressiva, simbólica e afetiva, na forma com que muitas juventudes experimentam a sua condição juvenil. O trabalho, assim como a escola, possibilita ao jovem vivenciar sua juventude, e, ainda, se integrar a um grupo social.

Importa destacar que a designação juventudes trabalhadoras, empregada neste trabalho, integra os jovens que trabalham a um grupo social específico, mas que não elimina ou se sobrepõe, aos outros grupos que também dele fazem parte. $\mathrm{O}$ autor destaca que as mudanças ocorridas no mundo e nas relações de trabalho, aliadas aos diferentes modos de inserção e postura dos jovens, vão construindo as juventudes em processo dinâmico e contínuo.

[...] é necessário situar as mutações que vêm ocorrendo no mundo do trabalho que, no Brasil, vem alterando as formas de inserção dos jovens no mercado, com uma expansão das taxas de desemprego aberto, com o desassalariamento e a geração de postos de trabalho precários, que atingem, principalmente, os jovens de camadas populares, delimitando o universo de experiências e seu campo de possibilidades (DAYRELL, 2007, p. 1108).

Com base na revisão de diversos estudos no campo das juventudes, Picanço (2015) destaca que há muitos fatores que levam os jovens ao trabalho. Por exemplo, não, apenas, o fato de poder contribuir com a renda familiar, mas também o alcance de certa autonomia. É possível ressaltar que a associação entre pobreza e o ingresso de jovens no mercado de trabalho tem contornos culturais mais complexos, pois este ingresso configura-se, no entendimento social, como uma realidade quase compulsória na vida dos jovens pobres. "Para muitos adolescentes e jovens, trabalhar é parte da definição e expectativa de vida, seja pelo processo de autonomia ("ter meu próprio dinheiro") seja, como é recorrente nas falas, "para ajudar em casa" (PICANÇO, 2015, p. 571). Espera-se, por parte dos jovens pobres, uma inserção laboral mais precoce.

Considerando as diversas circunstâncias e motivos que levam os jovens a optarem pelo trabalho, mesmo que esta opção não seja, muitas vezes, trazida a consciência, como uma 
possibilidade real de escolha, observamos sempre a existência de condições e condicionantes individuais e familiares muito distintos, não sendo possível fazer generalizações únicas sobre estes. Mas, sobretudo, o que se evidencia no campo do trabalho para as juventudes, quando não resguardado devidamente por políticas públicas efetivas, é seu potencial de reprodução de padrões socioculturais que mantêm vulneráveis os jovens.

Helena Abramo (2005) chama a atenção para as diferenças existentes entre o trabalho das juventudes nas diferentes regiões do país. Não há uma única realidade de condições, porém, tanto nos grandes centros urbanos como nas áreas rurais, observamos situações de precariedade. Conforme cada contexto se apresenta, alguns jovens são submetidos ao trabalho desde à infância, sem registro formal e em situações ainda análogas ao trabalho escravo. Sem remuneração, troca-se o trabalho por alimentação, sem garantia da continuidade dos estudos, bem como de seus direitos.

Abramo (1997) destaca o fato de a grande maioria das ações governamentais, destinada ao público jovem, ter como pano de fundo o discurso da ressocialização. São ações, em sua maioria, voltadas para jovens em desvantagem social ou em situação de risco (para a sociedade e para si próprios), como se convencionou chamar, ainda aqueles envolvidos em tráfico de drogas, atos de violência ou os submetidos a exploração sexual e a situação de rua.

Pode-se dizer que a maior parte desses programas está centrado na busca de enfrentamento dos problemas sociais que afetam a juventude, (cuja causa ou culpa se localiza na família, na sociedade ou no próprio jovem, dependendo do caso e da interpretação), mas, no fundo, tomando os jovens eles próprios como problemas sobre os quais é necessário intervir, para salvá-los e reintegrá-los à ordem social (ABRAMO, 1997, p. 26).

Os programas de capacitação profissional e de encaminhamento para o mercado de trabalho, também foram artifícios usados no processo de ressocialização das juventudes, principalmente no que tange as juventudes em situação de vulnerabilidades. Para além de suas boas intenções, em boa parte desses programas o que se busca "é uma contenção do risco real ou potencial desses garotos, pelo seu afastamento das ruas ou pela ocupação de suas mãos ociosas" (ABRAMO, 1997, p. 26).

Os jovens, quando não assistidos e devidamente ocupados, são em si, segundo este pensamento, um risco potencial a boa ordem social. Desta forma, ocupar inclusive suas mentes, torna-se necessário. Consideramos que, em muitos casos, o trabalho e a formação profissional oferecidas precocemente aos jovens, prestam-se a isso. Para Abramo (1997), as iniciativas governamentais, por meio da criação de leis e propostas, que incentivam o trabalho na juventude, mostram-se em essência, como fator de reprodução de dimensões da desigualdade 
social. Uma vez que os jovens, ainda em formação, são impelidos a dividir sua rotina diária entre trabalho, escola e ainda muitas vezes, obrigações domésticas, observamos então a manutenção de um ciclo de exclusão social.

O trabalho, muitas vezes precário, não oferece condições de desenvolvimento, a escola revela-se pouco atrativa e desconectada do mundo real, gerando mais vulnerabilidade e sem haver perspectivas de melhorias para o futuro. Porém, frente a este quadro, é preciso criar melhores condições de trabalho para os jovens, com atenção para sua inserção nas empresas. Como aponta Picanço (2015), mesmo se tratando de uma condição ambígua, de inclusão e exclusão, o trabalho na juventude revela-se também como um fator de transformação social.

\section{Um panorama das políticas para a educação profissional das juventudes}

Numa leitura histórica, podemos tomar como recorte inicial, neste estudo sobre a educação profissional dos jovens brasileiros, a Consolidação das Leis do Trabalho (CLT) promulgada por meio da Lei $\mathrm{n}^{\circ}$ 5.542/43 (BRASIL, 1943). O quarto capítulo da CLT (art. 402 ao 441) trata da proteção do trabalho do menor, onde é possível encontrar as diretrizes sobre a contratação de jovens, sintetizando as legislações, até então, existentes.

A promulgação da CLT, como uma lei que garantia as conquistas dos direitos dos trabalhadores, em geral, e dos jovens, em específico, teve como um de seus objetivos modificar o quadro das péssimas condições de trabalho encontradas pelos jovens. Até então, as jornadas de trabalho extensas nas fábricas, os trabalhos perigosos e insalubres ou que atentavam contra sua integridade física e moral. Além do início muito precoce, como ocorria no meio rural, conforme aponta Picanço (2015). Esta discussão também lançava luz sobre a baixa escolaridade dos jovens trabalhadores brasileiros, o abandono da educação formal e a falta de preocupação, por parte dos empregadores e das políticas de governo, com a formação profissional e educacional desta mão de obra.

A ideia que pairava, coerente com o projeto de nação esboçado na época, era da necessidade de formar mão de obra qualificada e garantir esta qualificação, mesmo que, ainda, no campo apenas técnico de aprendizado dos ofícios, às futuras gerações em prol do crescimento do país. Segundo aponta Ricardo Fonseca (2015, p. 86), a “origem do contrato de aprendizagem remonta à Constituição de 1937, quando o Estado Novo, personificado em Getúlio Vargas, visava iniciar a industrialização no Brasil”.

Com a CLT, em 1943, regulamentou-se o contrato de trabalho para adolescentes de 12 a 18 anos, resguardando a estes os recentes direitos adquiridos pelos demais trabalhadores. A 
criação dos Serviços Nacionais de Aprendizagem, em 1946, garantiu, ainda, a estes jovens trabalhadores o advento de uma qualificação profissional, ofertada a todos em instituições qualificadas de formação profissional.

Para Fonseca (2015), grande mérito se deve a este processo ocorrido no país, com a garantia do trabalho para os jovens na CLT e a preocupação com sua formação profissional, possibilitada a partir do tripé empresa-serviço de aprendizagem-aprendiz/família. Porém, a rápida industrialização do país converteu-se, em muitos casos, em um processo de aumento das desigualdades e injustiças sociais, às quais os jovens trabalhadores continuaram expostos.

O modelo Getulista, porém, tornou-se insuficiente, visto que a sociedade plural e urbana, massiva e globalizada do século XXI, passou a exigir novas diretrizes, superados que foram os processos da sociedade industrial, que se converteram pela demanda da chamada "sociedade pós-industrial" ou "sociedade do conhecimento" (FONSECA, 2015, p. 86).

O texto original da CLT (1943) foi alterado e adequado em diversos momentos, conforme os avanços ou retrocessos históricos da própria sociedade brasileira. No campo social, as discussões a respeito das juventudes foram ganhando espaço, com atenção especial às temáticas do trabalho e da educação. A garantia de acesso a postos de trabalho mais qualificados, assim como também o acesso e a permanência na educação formal eram pautas constantes.

A Lei n 229/67 (BRASIL, 1967), em meio ao regime militar, propôs diversas mudanças na CLT, inclusive no campo do trabalho do menor. Neste texto, ainda, podemos observar a autorização do trabalho a partir dos 12 anos, desde que garantida a sua frequência à escola, assegurando sua formação, ao menos, em nível primário. As funções a serem executadas pelos jovens no trabalho deveriam ser de nível leve e não se mostrar nocivas a sua saúde e ao seu desenvolvimento normal (BRASIL, 1967). Chamamos a atenção para a questão da normalidade citada pelo texto da lei. Ao definir determinados padrões para o desenvolvimento dos jovens trabalhadores, como sendo normais, a lei considera (ou desconsidera) como fora da normalidade outras possibilidades de desenvolvimento que podem se apresentar às juventudes. Portanto, há limites nesta discussão.

Em 1987, a Lei n ${ }^{\circ}$ 94.338/87 (BRASIL, 1987), institui o Programa Bom Menino, que girava em torno da iniciação do trabalho do menor assistido. Este decreto regulamentou o art. $4^{\circ}$ da Lei $n^{\circ} 2.318 / 86$ e segundo aponta Picanço (2015), possibilitou que os empregadores passassem a não pagar os encargos trabalhistas referentes aos jovens trabalhadores. Segundo a autora (2015, p. 573), as normas gerais apontadas pelo programa eram que os sujeitos: “a) 
frequentassem a escola; b) fossem menores assistidos em situação irregular; e, c) para trabalho na jornada de 4 horas diárias sem vínculo com a previdência".

As empresas deveriam admitir, pelo menos, $5 \%$ de jovens, conforme a proporção de funcionários. Aos jovens, deveria ser paga uma bolsa (bolsa de iniciação ao trabalho), com recomendação de não inferir a 50\% do salário mínimo vigente. Poderia ser anotada na carteira de trabalho, sem que fosse considerado vínculo empregatício.

Estes movimentos, segundo aponta Picanço (2015), iam no sentido oposto das experiências internacionais que já se configuravam na época. Enquanto o Brasil, continuava a incentivar a contratação de jovens, inclusive com isenções às empresas, outros países apontavam para um maior investimento no processo de escolarização dos jovens e, por consequência, num alongamento da inatividade laboral. Nestes países, a pressão exercida para o início da vida profissional precoce é deixada de lado, cabendo aos jovens os estudos, trabalhos voluntários, trabalhos de verão (nas férias) ou em meio-período que não prejudiquem sua vida escolar.

Para autores como Picanço (2015) e Márcio Pochmann (2000), não há no Brasil até o final da década de 80 do século 20 , uma preocupação com a erradicação do trabalho infantojuvenil. A força de trabalho de crianças, adolescentes e jovens, se mostrou oscilante no decorrer da história, sendo ora mais evidente em números, com grandes contingentes, ora mais invisibilizado, sem grande importância. Não existiam, portando, políticas públicas efetivas e nem a regulação mais precisa do trabalho para esse público. Pelo contrário, havia, socialmente, um incentivo à contratação de jovens, principalmente das camadas mais pobres, tanto no meio urbano quanto rural.

Pochmann (2000), ainda, destaca que, entre muitos empregadores do país, sempre houve a ideia de que os jovens são profissionais menos preparados para os postos de trabalho e com isso menos produtivos também, gerando resistências a estas contratações. Este autor destaca que a qualificação pode ser um determinante para o potencial ingresso das populações mais jovens no mundo do trabalho. Porém, há outros fatores sociais e econômicos presentes neste processo, sendo os jovens sempre os mais afetados nas oscilações ocorridas no mercado de trabalho e nas mudanças políticas do país, por sua falta de experiência profissional e por estarem no início de suas carreiras.

Com o processo de redemocratização do país durante a década de 80, que culmina com a promulgação da Constituição Federal de 1988 (BRASIL, 1988), vemos surgir novos sentidos na atenção à infância, a adolescência e juventude. A constituição, considerada a mais cidadã da 
história, altera a idade mínima para o ingresso no mercado de trabalho, além de assegurar aos jovens (como a todos os indivíduos), direitos nunca antes obtidos na história do país.

Com relação às condições e à idade, passa a ser proibido "o trabalho noturno, perigoso ou insalubre aos menores de dezoito e de qualquer trabalho a menores de quatorze anos, salvo na condição de aprendiz" (BRASIL, 1988, art. $7^{\circ}$ ). Este texto foi, posteriormente, alterado por meio da emenda constitucional no 20 de 1998 que passa a proibir "trabalho noturno, perigoso ou insalubre a menores de dezoito e de qualquer trabalho a menores de dezesseis anos, salvo na condição de aprendiz, a partir de quatorze anos" (art. $\left.1^{\circ}\right)$.

A proibição do trabalho aos menores de 14 anos em quaisquer situações, sendo somente autorizado a partir desta idade (os jovens entre 14 e 15 anos) na condição de aprendiz, lança uma nova luz ao campo do trabalho na juventude, demarcando os limites da infância e a crescente preocupação com o acompanhamento dos modos de inserção dos jovens no mundo do trabalho. Garante-se seus direitos como sujeitos em desenvolvimento, como estudantes e também como trabalhadores, com especial atenção aos fatores, sociais, psicológicos, econômicos e individuais. Aos jovens de 16 e 17 anos, é permitido o trabalho em outros tipos de contrato. Mas até completarem 18 anos, estes devem ser assistidos pelo responsável legal.

Em 1990, um importante marco à garantia dos direitos da criança e do adolescente foi a aprovação do Estatuto da Criança e do Adolescente (ECA). A Lei nº 8.069/90 (BRASIL, 1990), que tem como pressuposto o princípio da proteção integral, confere a todas as crianças e adolescentes direitos civis, políticos, econômicos, sociais e culturais em caráter prioritário e de atenção especial. O capítulo V do ECA - Do Direito à Profissionalização e à Proteção no Trabalho -, reafirma a proibição do trabalho aos menores de 14 anos e versa sobre as formas que devem ser construídas as políticas de trabalho para a juventude no Brasil, com foco em seu aspecto educacional e de aprendizado.

Em seus artigos 68 e 69, o ECA traz importantes considerações ao campo educacional, na construção dos cursos de formação profissional que passam a ser essenciais aos jovens trabalhadores.

Art. 68. O programa social que tenha por base o trabalho educativo, sob responsabilidade de entidade governamental ou não-governamental sem fins lucrativos, deverá assegurar ao adolescente que dele participe condições de capacitação para o exercício de atividade regular remunerada.

$\S 1^{\circ}$ Entende-se por trabalho educativo a atividade laboral em que as exigências pedagógicas relativas ao desenvolvimento pessoal e social do educando prevalecem sobre o aspecto produtivo.

$\S 2^{\circ} \mathrm{A}$ remuneração que o adolescente recebe pelo trabalho efetuado ou a participação na venda dos produtos de seu trabalho não desfigura o caráter educativo. 
Art. 69. O adolescente tem direito à profissionalização e à proteção no trabalho, observados os seguintes aspectos, entre outros:

I - respeito à condição peculiar de pessoa em desenvolvimento;

II - capacitação profissional adequada ao mercado de trabalho (BRASIL, ECA, Art. 68/69, 1990).

Neste cenário, Fonseca (2015) chama a atenção para o processo histórico ocorrido no Brasil, de ruptura de uma doutrina minorista, representada por uma visão meramente assistencialista voltada aos jovens carentes. Com o ECA em 1990 e a Lei da Aprendizagem em 2000, passa a existir uma doutrina em prol da proteção integral dos adolescentes aprendizes, que inspirada em tendências internacionais, trouxe para o campo da proteção do trabalho dos jovens expressivos avanços à educação.

Ao refletir sobre os caminhos percorridos na atenção às juventudes em nosso país, percebemos que estes caminhos, na maioria das vezes, respaldados por interesses do capital, em poucos momentos se dedicaram à compreensão das juventudes como sujeitos de seu tempo e detentores de uma identidade geracional própria. Há que nos atentarmos que cada geração de jovens revela as dificuldades e incoerências de seu tempo, assim como seus avanços e progressos.

Contar esta história, por meio das leis e fatos históricos, nos parece também uma forma de narrar as trajetórias das juventudes e daqueles que lutam por seus direitos. Visto que qualquer mudança só é possível a partir da luta e do embate constantes, travados nos diversos espaços.

Neste cenário estudado, importa destacar que, ao olhar as juventudes e suas manifestações, como um problema que deve ser neutralizado por meio do trabalho e da educação, impede-se a existência e emergência de um potencial criativo e transformador, os quais identificamos como característicos das juventudes.

\section{A aprendizagem profissional: caminhos para a proteção integral}

A inserção laboral de jovens no Brasil tem atendido a diferentes interessantes econômicos e políticos, conforme o momento histórico vigente. A partir dos anos 2000, com a consolidação do ECA e outras políticas de governo, a eminência de movimentos sociais dos jovens, vemos a possibilidade de construir novos significados para esta prática social. Além de garantir o acesso dos jovens às vagas de emprego, é preciso também assegurar seu desenvolvimento de maneira plena e saudável, por meio da qualificação profissional e formas de trabalho mais justas nos termos do trabalho decente. 
A Lei $\mathrm{n}^{\circ} 10.097$ de 19 de dezembro 2000 (BRASIL, 2000), conhecida como a Lei da Aprendizagem Profissional, surgiu como uma proposta para realizar, de modo assegurado, a inclusão dos jovens brasileiros no mercado de trabalho formal. Segundo Francisco de Moraes (2012), por um longo período, houve declínio de demanda da aprendizagem profissional no país, principalmente pelos poucos esforços de fiscalização trabalhista e o pouco investido em políticas de formação. A lei garante aos jovens de 14 a 24 anos a possibilidade de adentrar no mercado de trabalho na condição de jovem aprendiz, fornecendo-lhes uma formação profissional básica.

Considerando os impasses históricos que atravessaram a relação entre juventude e trabalho, a lei que altera o texto da CLT de 1943, reafirma o direito à profissionalização previsto na Constituição Federal de 1988, no Estatuto da Criança e do Adolescente (ECA) de 1990 e, mais recentemente, no Estatuto da Juventude, promulgado como lei em 2013. (BRASIL, 2013)

A Lei $\mathrm{n}^{\mathrm{o}}$ 10.097/00, incorporando a doutrina da proteção integral dos adolescentes, alterou a CLT. Ao preservar o modelo anterior, propôs a sua renovação, visando, com isso, aperfeiçoá-lo e torná-lo compatível com as necessidades de milhões de adolescentes que vivem nos mais variados rincões (FONSECA, 2015, p. 86).

A Lei da Aprendizagem Profissional (BRASIL, 2000) tem como objetivo garantir o acesso à qualificação adequada, visando a continuidade dos estudos dos jovens que, muitas vezes, abandonam as escolas para poder trabalhar.

Estudos demonstram que o desemprego e a rotatividade são muito maiores entre os jovens - não por que eles não sabem o que querem ou por que o mercado não os queira, mas por que, na grande maioria das vezes, o ingresso no mercado de trabalho se dá de forma precária, sem acesso à qualificação adequada e com jornadas que desestimulam a continuidade dos estudos (BRASIL, 2014, p. 9).

Em seu texto inicial a Lei $n^{\circ} 10.097 / 00$, previa a contratação de jovens aprendizes até os 18 anos de idade, conforme idade estabelecida pelo ECA. A partir de 2005, com a Lei $\mathrm{n}^{\circ}$ 11.180 (BRASIL, 2005), esta idade é ampliada com a possibilidade de contratação jovens como aprendizes até os 24 anos. Esta alteração ocorreu como uma alternativa para a redução das taxas de desemprego cada vez mais crescentes entre os mais jovens e também para atender diversas demandas do mundo do trabalho, cada vez mais competitivo e exigente no que diz respeito as qualificações e experiências. Importante destacarmos que esta limitação de idade máxima prevista, não se aplica, conforme a lei, às pessoas com deficiência. 
As diretrizes referendadas nestas leis compreendem o jovem como um ser em desenvolvimento, preconizando que, além de exercer atividade profissional no contexto de uma empresa formal, o jovem deverá realizar um curso de formação oferecido por uma instituição educacional. Esta formação técnico-profissional, segundo a Lei $\mathrm{n}^{\circ} 10.097$, refere-se às “atividades teóricas e práticas, metodicamente organizadas em tarefas de complexidade progressiva desenvolvidas no ambiente de trabalho" (BRASIL, 2000, art. 428).

Tais atividades devem ser organizadas pelas empresas e por entidades qualificadas, por meio de programas de aprendizagem. As atividades desenvolvidas pelos jovens nas empresas devem preservar sua condição de aprendizado e seguir a Classificação Brasileira de Ocupações (CBO), conforme o seguimento da empresa. O jovem deverá ter um Plano de Atividades a ser seguido, descrito em seu contrato de trabalho. Sendo a própria natureza do contrato do jovem aprendiz diferenciada.

Contrato de aprendizagem é o contrato de trabalho especial, ajustado por escrito e por prazo determinado, em que o empregador se compromete a assegurar ao maior de 14 (quatorze) e menor de 24 (vinte e quatro) anos inscrito em programa de aprendizagem formação técnico-profissional metódica, compatível com o seu desenvolvimento físico, moral e psicológico, e o aprendiz, a executar com zelo e diligência as tarefas necessárias a essa formação (BRASIL, 2005, art. $3^{\circ}$ ).

Este contrato de trabalho não poderá exceder o tempo de 2 anos, sendo firmado entre a empresa, o jovem (na presença do responsável legal quando menor) e endossado por uma instituição educacional de formação técnico-profissional. Ao jovem é garantido receber um salário mínimo hora, de acordo com sua jornada de trabalho semanal, que não poderá ultrapassar 30 horas semanais, em no máximo 6 horas diárias de trabalho divididas entre a empresa e o curso de formação, conforme dias estabelecidos no contrato.

O contrato de Aprendizagem somente poderá ser finalizando antes do prazo determinado em casos de desempenho insuficiente ou de inadaptação do aprendiz ao trabalho, por falta indisciplinar grave (conforme descritas na própria CLT), por faltas injustificadas na escola que impliquem sua perda do ano letivo ou a pedido do próprio aprendiz, não sendo necessário a este cumprir ou pagar aviso prévio. Nos casos de desempenho insuficiente ou inadaptação as empresas deverão, tendo em vista o caráter educacional e formativo da contração dos jovens, realizar ações de acompanhamento e feedbacks constantes, cabendo as instituições formadoras também este acompanhamento. O desligamento somente poderá ser realizado mediante laudo de avaliação elaborado pela entidade de formação. 
A lei ainda estabelece em seu texto a obrigatoriedade de contratação de aprendizes por todas as empresas, fixando a porcentagem a ser considerada.

Os estabelecimentos de qualquer natureza são obrigados a empregar e matricular nos cursos dos Serviços Nacionais de Aprendizagem número de aprendizes equivalente a cinco por cento, no mínimo, e quinze por cento, no máximo, dos trabalhadores existentes em cada estabelecimento, cujas funções demandem formação profissional (BRASIL, 2000, art. 429).

Poderão se candidatar às vagas de jovens aprendizes, todos os jovens, dentro das idades mencionadas, que estejam matriculados no ensino regular ou que já apresentem o ensino médio completo e que não tenham sido jovens aprendizes em contrato de 2 anos. A matrícula e a frequência à escola são aspectos que devem ser considerados na contratação e manutenção dos jovens nos programas de aprendizagem. A seleção dos jovens para os postos de trabalho cabe às próprias empresas ou às entidades que se prestam a este fim. Cabe ao MTE a fiscalização do cumprimento da lei, por meio de visitas às empresas e às instituições formadoras.

Os Serviços Nacionais de Aprendizagem são, segundo a lei, as instituições qualificadas para o oferecimento dos programas e devem ter a primazia na escolha e matrícula por parte das empresas. As empresas somente podem matricular os jovens em outras instituições, caso não encontrem vagas nestes primeiros.

A resolução do Conselho Nacional dos Direitos e do Adolescente (CONANDA) (BRASIL, 2001) trata das entidades sem fins lucrativos (ESFL) que apresentem como objetivo a assistência ao adolescente e à educação profissional. As ESFL, que historicamente cumpriram um importante papel na formação de jovens e foram essenciais na reformulação das leis de empregabilidade e qualificação dos jovens, devem apresentar estrutura adequada à realização dos programas de aprendizagem e cumprir todas as normativas legais previstas. Todavia, no campo da formação educacional, parecia haver uma lacuna, principalmente pela falta de diretrizes que estabeleçam minimamente os caminhos a serem seguidos por esta formação, garantindo assim, conforme as leis, o desenvolvimento integral dos jovens. A portaria $\mathrm{n}^{\circ} 723$ de 2012 do MTE (BRASIL, 2012), objetivou criar um Cadastro Nacional de Aprendizagem Profissional (CNAP) e um Catálogo Nacional de Programas de Aprendizagem Profissional (CONAP), além de definir as diretrizes operacionais e pedagógicas dos programas.

Em uma análise histórica, é possível compreender que a primeira necessidade residia em garantir condições dignas de trabalho, frente as desigualdades sociais e as condições de trabalho precárias, das quais os jovens pobres continuavam a ser excluídos. Por ocasião dos avanços no campo da conquista de direitos, passou-se a obrigatoriedade de contratação de 
jovens em todas as empresas e sua matrícula concomitante em um curso de formação profissional. Mais adiante, vemos, então, a preocupação das leis não somente com a inserção dos jovens, mas também com uma formação humana e científica devidamente contextualizados.

Os cursos vinculados ao programa de formação profissional deverão contemplar (BRASIL, 2012), os jovens em seu desenvolvimento de maneira integral, possibilitando ao jovem, condições de aprender e refletir sobre sua prática profissional na empresa e sua inserção profissional no contexto de uma sociedade mais ampla. Além de discutir suas atividades na empresa que devem ir, de acordo com o segmento em que atuam, os jovens deverão estudar conteúdos que contemplem sua formação nos aspectos sociais, humanos e cidadãos, visando sua inserção em uma sociedade, na qual sejam capazes de intervir e transformar. Assim, o trabalho do jovem na empresa deverá ser concomitante com sua formação educacional na instituição de ensino.

Destacamos, então, o papel da formação educacional no desenvolvimento do jovem aprendiz, sendo este capaz de gerar uma reflexão sobre sua atuação e uma formação em serviço.

As dimensões teórica e prática da formação do aprendiz devem ser pedagogicamente articuladas entre si, sob a forma de itinerários formativos que possibilitem ao aprendiz o desenvolvimento da sua cidadania, a compreensão das características do mundo do trabalho, dos fundamentos técnico-científico e das atividades técnico-tecnológicas específicas à ocupação (BRASIL, MTE, 2012, art. $10 \S 1^{\circ}$ ).

Esta nova ideia, segundo Fonseca (2015), proporciona uma revolução na aprendizagem profissional, pois ela passa a não estar mais atrelada, como no passado, a profissões específicas ou ofícios. Buscam-se, então, competências consideradas básicas à execução de qualquer trabalho, em consonância com as constantes mudanças do mundo do trabalho e que devem ser pensadas de maneira metódica e progressiva.

A formação deve buscar alternar experiências, teorias e práticas, a fim de gerar um constante diálogo entre ambos os campos. "O direito à profissionalização, prioritário para adolescentes e jovens e essencial para adultos e pessoas com deficiência, assume relevância estratégica no momento em que se vivencia a chamada "sociedade do conhecimento" (FONSECA, 2015, p. 96).

Nesta perspectiva, as diretrizes curriculares traçadas, visam ao desenvolvimento do jovem enquanto trabalhador e cidadão, primando por seus aspectos sociais e profissionais. Dáse especial atenção às juventudes que se apresentam em situações de vulnerabilidades e aos jovens com deficiência. 
Em relação ao conteúdo a ser abordado durante os cursos de formação, é possível encontrar as seguintes propostas.

a) Comunicação oral e escrita, leitura e compreensão de textos e inclusão digital; b) Raciocínio lógico-matemático, noções de interpretação e análise de dados estatísticos; c) Diversidade cultural brasileira; d) Organização, planejamento e controle do processo de trabalho e trabalho em equipe; e) Noções de direitos trabalhistas e previdenciários, de saúde e segurança no trabalho e do Estatuto da Criança e do Adolescente - ECA; f) Direitos humanos, com enfoque no respeito à orientação sexual, raça, etnia, idade, credo religioso ou opinião política; g) Educação fiscal para o exercício da cidadania; h) Formas alternativas de geração de trabalho e renda com enfoque na juventude; i) Educação financeira para o consumo de informações sobre o mercado e o mundo do trabalho; j) Prevenção ao uso de álcool, tabaco e outras drogas; k) Educação para a saúde sexual reprodutiva, com enfoque nos direitos sexuais e nos direitos reprodutivos e relações de gênero; 1) Políticas de segurança pública voltadas para adolescentes e jovens e; m) Incentivo à participação individual e coletiva, permanente e responsável, na preservação do equilíbrio do meio ambiente, com enfoque na defesa da qualidade ambiental como um valor inseparável do exercício da cidadania (BRASIL, MTE, 2012, art. 10 III).

Em uma análise geral, os conteúdos estabelecidos apresentam uma grande variedade de temáticas a serem abordadas na formação dos jovens. Estes giram, ora em torno de uma formação profissional mais específica, mesmo que não ligados a um único ofício, ora vão na direção do que podemos chamar de uma formação cidadã.

Despertam maior atenção, neste momento, conteúdos como: diversidade cultural, ECA, Direitos Humanos com enfoque no respeito à orientação sexual, raça, etnia, idade, credo religioso ou opinião política, educação para a saúde sexual e reprodutiva, relações de gênero e meio ambiente. Tais temáticas parecem aflorar mediante as discussões sociais que aparecem na cena pública da atualidade.

Quanto ao perfil dos docentes encarregados de ministrar as atividades teóricas dos programas de aprendizagem, não há na lei nenhuma especificidade de formação e experiência. É previsto que as instituições contem com quadro técnico-docente devidamente qualificado e recursos de apoio a execução dos programas. Sendo que, ao término do curso, será concedido ao jovem concluinte um certificado de qualificação profissional.

Cada instituição, sejam os Serviços Nacionais de Aprendizagem ou sem fins lucrativos, constrói o seu programa de aprendizagem de modo particular, respeitando tais diretrizes operacionais e pedagógicas. O tempo de contrato poderá ser diferente (não extrapolando os 2 anos permitidos), como também alterações nas formas de abordagem da estrutura curricular do curso e na carga horária semanal. 
A própria ação docente se modifica, assim como as estratégias de ensino e aprendizagem e a autonomia dos jovens, a rigidez ou flexibilidade com que o jovem é tratado, entre outros aspectos. Porém, acreditamos que o cerne de todos os programas oferecidos nestas instituições deva ser o mesmo: possibilitar condições de acesso ao trabalho e aprendizagens significativas para jovens em situação de vulnerabilidade social, com vistas a sua formação integral, enquanto trabalhador e cidadão.

A aprendizagem é um instituto que cria oportunidades tanto para o aprendiz quanto para as empresas, pois dá preparação ao iniciante de desempenhar atividades profissionais e de ter capacidade de discernimento para lidar com diferentes situações no mundo do trabalho. Ao mesmo tempo, permite às empresas formarem mão de obra qualificada, algo cada vez mais necessário em um cenário econômico em permanente evolução tecnológica (BRASIL, 2014, p. 11).

Concordamos com a colocação acima, porém destacamos que, apesar do duplo benefício (aprendiz-empresa), em nossa análise, não há por parte de algumas empresas a intenção expressa do desenvolvimento dos jovens como trabalhadores e cidadãos, reconhecendo-os, apenas, como cotas de contratação estabelecidas pela lei. Mesmo sem negar os avanços já conquistados, é preciso reconhecer as limitações e caminhar na busca de processos de inclusão efetivos, por meio de novas metodologias e estratégias que visam a maior participação dos jovens nas empresas e nos programas de formação profissional.

Em caráter mais recente, temos a aprovação do Estatuto da Juventude (EJ), que por meio Lei ${ }^{\circ}$ 12.852/13 (BRASIL, 2013), dispôs a respeito dos direitos dos jovens (de 15 a 29 anos) e das políticas públicas para esta faixa etária. Em sua sessão III, o EJ trata do direito do jovem à profissionalização, ao trabalho e à renda, resguardando no art. 14 que o trabalho dos jovens deve ser "exercido em condições de liberdade, equidade e segurança, adequadamente remunerado e com proteção social".

Em uma primeira análise, é possível argumentar que o Estatuto da Juventude aponta para as tendências já esboçadas em outras leis, reafirmando o dever do Estado em garantir as condições de acesso ao trabalho digno, com vistas à formação qualificada das novas gerações.

\section{Considerações finais}

As mudanças no mundo trabalho e na inclusão profissional de jovens trabalhadores não ocorreram alheias às mudanças na área da educação. Pelo contrário, trabalho e educação demonstram íntimas relações no percurso histórico brasileiro. Ambos são, ao mesmo tempo, 
fatores de transformação e de controle social. Portanto, formar profissionais qualificados e reflexivos para uma ação, cada vez contextualizada e inovadora, parece ser um constante desafio.

A educação brasileira, em seu aspecto mais geral, bem como, especificamente, a educação profissional, desenvolveram-se a partir de constantes discussões e embates, gerados no meio social e acadêmico, sendo influenciadas por mudanças econômicas e políticas. "A história da educação brasileira é necessariamente uma história de hegemonias, de luta entre classes dominantes e dominadas e, consequentemente, dos interesses de cada um" (SANTOS, 2010, p. 35) e isto tem impacto importante na educação profissional das nossas juventudes. Tais interesses aparecem impressos em propostas de governo, em documentos nacionais e internacionais, voltados à construção dos modelos de educação e escola, aqui apresentados.

As transformações na educação brasileira, principalmente a partir da LDB/96, trazem importantes mudanças ao campo da educação profissional. Avança de uma proposição voltada ao fazer técnico, para uma concepção de sujeito crítico capaz de intervir em seu meio social e no mundo do trabalho.

A ação docente na educação profissional deve configurar-se por meio da mediação constante, que possa levar os alunos ao desenvolvimento das competências necessárias à sua atuação profissional. A reflexão sobre seu papel, sobre o profissional que se está formando, para qual mundo e sociedade, complementam sua atuação.

Segundo Vera Candau (1995), a escola e a educação devem ter o papel de humanizar as pessoas, levando-as a aquisição de conhecimentos e valores, com vistas a conquista do pleno exercício da cidadania. Assim, a formação de jovens para o mundo do trabalho não deve ser voltada exclusivamente para os valores do mercado e do capitalismo, os quais pressionam, hegemonicamente, para uma formação utilitarista, na busca por resultados econômicos. Entendemos que, muito além de formar mão de obra qualificada para o exercício de diversas funções nas empresas, a formação profissional de jovens aprendizes precisa formar para a reflexão e crítica, assim como para a transformação social. “Torna-se necessário a construção de uma escola que forma crianças e jovens construtores ativos da sociedade, capazes de viver no dia a dia, nos distintos espaços sociais, uma cidadania consciente, crítica e militante" (CANDAU,1995, p. 15). 


\section{REFERÊNCIAS}

ABRAMO, Helena. Considerações sobre a tematização social da juventude no Brasil. Revista Brasileira de Educação, n. 5-6, 1997.

ABRAMO, Helena. Retratos da juventude brasileira: análises de uma pesquisa nacional. São Paulo: Instituto da Cidadania/Fundação Perseu Abramo, 2005.

ABRAMO, Laís. Trabalho decente e juventude no Brasil: a construção de uma agenda. Mercado de Trabalho - conjuntura e análise, n. 55, IPEA, p. 39-44, 2013.

ABRAMOVAY, Miriam Juventudes na escola, sentidos e buscas: Por que frequentam? Brasília, DF: Flacso - Brasil, OEI, MEC, 2015.

BOCK, Silvio Duarte. Orientação profissional para as classes pobres. São Paulo: Cortez, 2010.

BRASIL. Decreto n. 7.566, de 23 de setembro de 1909. Dispõe sobre a criação das escolas de artificies. Diário Oficial da União, Brasília, DF, 29 set. 1909. Disponível em: https://www2.camara.leg.br/legin/fed/decret/1900-1909/decreto-7566-23-setembro-1909525411-publicacaooriginal-1-pe.html. Acesso em: 05 de abril de 2019.

BRASIL. Código de menores. Decreto n. 17.943-A, de 12 de outubro de 1927. Consolida as leis de assistência e proteção a menores. Coleção de Leis do Brasil, Brasília, DF, 31 dez. 1927, p. 476. Disponível em: https://www2.camara.leg.br/legin/fed/decret/1920-1929/decreto17943-a-12-outubro-1927-501820-publicacaooriginal-1-pe.html. Acesso em: 05 de abril de 2019.

BRASIL. Consolidação das Leis do Trabalho. Lei n. 5.452, de 1 de maio de 1943. Diário Oficial da União, Brasília, DF, 1 maio 1943. Disponível em:

http://www.planalto.gov.br/ccivil_03/decreto-lei/del5452.htm. Acesso em: 05 de abril de 2019.

BRASIL. Lei n. 8.621, de 10 de janeiro de 1946. Dispõe sobre a criação do Serviço Nacional de Aprendizagem Comercial e dá outras providências. Diário Oficial da União, Brasília, DF, 12 jan. 1946a. Disponível em: http://www.planalto.gov.br/ccivil_03/Decreto-Lei/19371946/Del8621.htm. Acesso em: 05 de abril de 2019.

BRASIL. Lei n. 8.622, de 10 de janeiro de 1946. Dispõe sobre a aprendizagem dos comerciários. Diário Oficial da União, Brasília, DF, 12 jan. 1946b. Disponível em: http://www.planalto.gov.br/ccivil_03/Decreto-Lei/1937-1946/Del8622.htm. Acesso em 05 de abril de 2019.

BRASIL. Lei n. 229, de 28 de fevereiro de 1967. Altera dispositivos da CLT, e dá outras providencias. Diário Oficial da União, Brasília, DF, 28 fev. 1967. Disponível em: http://www.planalto.gov.br/ccivil_03/decreto-lei/del0229.htm. Acesso em: 05 de abril de 2019.

BRASIL. Lei n. 94.338, de 18 de maio de 1987. Institui o Programa do Bom Menino. Coleção de Leis do Brasil, Brasília, DF, v. 4, p. 311, 1987. Disponível em: 
https://www2.camara.leg.br/legin/fed/decret/1980-1987/decreto-94338-18-maio-1987444199-publicacaooriginal-1-pe.html. Acesso em: 05 de abril de 2019.

BRASIL. Constituição da República Federativa do Brasil de 1988. Diário Oficial da União, Brasília, DF, 5 out. 1998. Disponível em:

http://www.planalto.gov.br/ccivil_03/constituicao/constituicao.htm. Acesso em: 05 de abril de 2019.

BRASIL. Estatuto da criança e do adolescente. Lei n. 8.069, de 13 de julho 1990. Diário Oficial da República Federativa do Brasil, Brasília, 1990. Disponível em: http://www.planalto.gov.br/ccivil_03/leis/18069.htm. Acesso em: 05 de abril de 2019.

BRASIL. Ministério da Educação. Lei de Diretrizes e Bases da Educação Nacional. Lei n. 9.394, de 20 de dezembro de 1996. Brasília: MEC, 1996. Disponível em: https://www2.camara.leg.br/legin/fed/lei/1996/lei-9394-20-dezembro-1996-362578publicacaooriginal-1-pl.html. Acesso em: 05 de abril de 2019.

BRASIL. Lei n. 10.097, de 19 de dezembro de 2000. Altera dispositivos da Consolidação das Leis do Trabalho - CLT, aprovada pelo Decreto-Lei n. 5.452, de 1 de maio de 1943. Diário Oficial da União, Brasília, DF, 20 dez. 2000. Disponível em: http://www.planalto.gov.br/ccivil_03/LEIS/L10097.htm. Acesso em: 05 de abril de 2019.

BRASIL. Resolução n. 74, de 13 de setembro de 2001. Conselho Nacional dos Direitos da Criança e do Adolescente - CONANDA. Dispõe sobre o registro e fiscalização das entidades sem fins lucrativos e dá outras providências. 2001. Disponível em:

http://www.mpgo.mp.br/portal/arquivos/2013/05/22/11_17_33_163_Resolu\%C3\%A7\%C3\% A3o_Conanda_n\%C2\%BA_74.pdf. Acesso em: 05 de abril de 2019.

BRASIL. Lei n. 5.598, de 1 de dezembro de 2005. Regulamenta a contratação de aprendizes, e dá outras providências. Diário Oficial da União, Brasília, DF, p. 2, 2 dez. 2005. Disponível em: https://www2.camara.leg.br/legin/fed/decret/2005/decreto-5598-1-dezembro-2005539401-norma-pe.html. Acesso em: 05 de abril de 2019.

BRASIL. Lei n. 11.741, de 16 de julho de 2008. Altera dispositivos e estabelece diretrizes para a educação profissional. Diário Oficial da União, Brasília, DF, 17 jul. 2008. Disponível em: http://www.planalto.gov.br/ccivil_03/_Ato2007-2010/2008/Lei/L11741.htm. Acesso em: 05 de abril de 2019.

BRASIL. Portaria n. 723, de 23 de abril de 2012. Criar o Cadastro Nacional de Aprendizagem Profissional - CNAP. Ministério do Trabalho e Emprego. 2012. Diário Oficial da União, Brasília, DF, 24 abr. 2012. Disponível em: http://www.normaslegais.com.br/legislacao/portaria-mte-723-2012.htm. Acesso em: 05 de abril de 2019.

BRASIL. Lei n. 12.852, de 5 de agosto de 2013. Estatuto da Juventude. Diário Oficial da União, Brasília, DF, 6 ago. 2013. Disponível em:

http://www.planalto.gov.br/ccivil_03/_ato2011-2014/2013/lei/112852.htm. Acesso em: 05 de abril de 2019. 
BRASIL. TEM, SIT, SPPE. Manual da aprendizagem: o que é preciso saber para contratar o jovem aprendiz. Brasília, 2014. Disponível em:

http://www.fieb.org.br/midia/2017/10/Manual-da-Aprendizagem-MTE-.pdf. Acesso em: 05 de abril de 2019.

BRASIL. Lei n. 9.579, de 22 de novembro de 2018. Altera o Decreto-Lei n. 5.598, de $1^{\circ}$ de dezembro de 2005. Diário Oficial da União, Brasília, DF, 23 nov. 2018. Disponível em: http://www.planalto.gov.br/ccivil_03/_ato2015-2018/2018/decreto/D9579.htm. Acesso em: 05 de abril de 2019.

CANDAU, Vera Maria. Tecendo a cidadania. 3. ed. Petropolis: Vozes, p. 126, 1995.

DAYRELL, Juarez. A escola "faz" as juventudes? Reflexões em torno da socialização juvenil. Educação e Sociedade, Campinas, v. 28 n. 100, p. 1105-1128, out. 2007.

DAYRELL, Juarez. Por uma pedagogia das juventudes: experiências educativas do Observatório da Juventude. 1. ed. Belo Horizonte: Mazza Edições, 2016.

FONSECA, Ricardo Tadeu Marques da. As formas de aprendizagem no brasil: questões emergentes. Rev. TST, Brasília, v. 81, n. 1, p. 78-96, jan./mar. 2015.

MORAES, Francisco de. Empresas-escola: educação para o trabalho versus educação pelo trabalho. 2. ed. São Paulo: Editora Senac São Paulo, 2012. 239 p.

PEREIRA, Maria G. dos Santos. Adolescentes trabalhadores: a construção de sentido nas relações de trabalho. In: Adolescências construídas: a visão da psicologia sócio-histórica. OZELLA, Sérgio (organizador). São Paulo: Cortez. 2003. 349 p.

PICANÇO, Felícia Silva. Juventude e trabalho decente no Brasil, uma proposta de mensuração. Caderno CRH (UFBA. Impresso), Salvador, v. 28, p. 569-590, 2015.

POCHMANN, Márcio. A batalha pelo primeiro emprego: as perspectivas e a situação atual do jovem no mercado de trabalho brasileiro. São Paulo: Publisher, Brasil, 2000.

SANTOS, Jurandir dos. Educação profissional e práticas de avaliação. São Paulo: Editora Senac São Paulo, 2010. 205 p.

\section{Como referenciar este artigo}

BARROS, Lucian da Silva; COSTA-RENDERS, Elizabete Cristina. A formação profissional das juventudes brasileiras: avanços e perspectivas nas interlocuções entre educação e trabalho. Revista on line de Política e Gestão Educacional, Araraquara, v. 24, n. 1, p. 189-209, jan./abr., 2020. e-ISSN:1519-9029. DOI: https://doi.org/10.22633/rpge.v24i1.13105

Submetido em: 12/09/2019

Revisões requeridas: $12 / 11 / 2019$

Aprovado em: 21/12/2019

Publicado em: 06/01/2020 